\title{
Sob o signo da luz e das sombras: o imaginário da autonomia em educação
}

\author{
Manuel Gonçalves Barbosa \\ Universidade do Minho
}

\section{Resumo}

O imaginário da autonomia tem um longo passado atrás de si e ainda hoje concita as maiores atenções em educação. Não obstante, devido à sua redefinição em termos de autossuficiência, cuidado de si mesmo, eu empreendedor, responsabilidade individual e autodeterminação obrigatória, questiona-se se essas ressignificações devem ser promovidas pela educação, pois, aparentemente, não se articulam com o lado luminoso desse imaginário, quer dizer, com a liberdade e a emancipação do ser humano. 0 nosso objetivo, depois de um transcurso histórico para dar profundidade ao tema do imaginário da autonomia, consiste em analisar as luzes e as sombras que presentemente envolvem esse imaginário e em perguntar, por referência à educação, se ainda vale a pena investir nesse imaginário e de que modo.

Palavras-chave: Imaginário. Autonomia. Ressignificações. Educação. 


\section{Under the sign of light and shadows: the imagery of autonomy in education}

The imagery of autonomy has a long past behind it and still concentrates major attention in education. Nevertheless, due to its redefinition in terms of self-sufficiency, selfcare, "I entrepreneur", individual responsibility and mandatory self-determination, it is questionable whether these redefinitions should be promoted by education, because apparently they are not articulated with the bright side of that imagery, that is, with the freedom and emancipation of mankind. Our goal, after an historic journey to deepen in the theme of imagery of autonomy, consists in analyzing the lights and the shadows which currently involve that imagery, and questioning, in regard to education, if it is still worthwhile to invest in that imagery and in what way.

Keywords: Imagery. Autonomy. Redefinitions. Education.

\section{Bajo el signo de la luz y las sombras: el imaginario de la autonomía en la educación}

El imaginario de la autonomía tiene un largo recorrido histórico y hoy por hoy concita todavía las mayores atenciones en educación. Sin embargo, debido a su redefinición en los términos de autosuficiencia, cuidado de sí mismo, yo emprendedor, responsabilidad individual y autodeterminación obligatoria, se cuestiona si estas resignificaciones tienen que ser promocionadas por la educación, pues, en apariencia, no se articulan con el lado luminoso del susodicho imaginario, es decir, con la libertad y la emancipación del ser humano. Nuestra intención, después de una mirada histórica sobre la temática del imaginario de la autonomía, es de analizar las luces y sombras que en el presente envuelven ese imaginario y en perguntar, por referencia al terreno de la educación, si vale la pena invertir en ese imaginario y como se puede hacerlo.

Palabras clave: Imaginario. Autonomía. Resignificaciones. Educación. 


\section{Introdução}

O discurso da autonomia, qual fênix renascida das próprias cinzas, está de volta à ribalta da discussão pedagógica e é preciso ponderar, numa altura em que a autonomia é social e politicamente redefinida como "autossuficiência", "cuidado de si”, "eu empreendedor", "responsabilidade individual" e "autodeterminação obrigatória", se a educação deve aderir, sem mais, a esse poderoso imaginário da área cultural ocidental.

Importa efetivamente averiguar se essas ressignificações são uma luz que potencia o reencontro com o projeto do empowerment, isto é, com a perspetiva da capacitação emancipatória do ser humano ao longo da vida, ou se são, pelo contrário, mais umas sombras que vêm ofuscar a concretização desse projeto no contexto e nas circunstâncias atuais.

Verdadeiramente, o discurso da autonomia nunca deixou de assediar as discussões em torno da educação e de mobilizar as atenções a seu respeito, pelo menos desde o iluminismo. Foi assim aquando da formulação dos princípios diretores de uma pedagogia consentânea com a autonomia do ser humano, ou seja, na transição do século XVIII para o século XIX, e continuou a ser do mesmo modo até muito recentemente, em parte pela incisiva retórica de figuras proeminentes do movimento pedagógico da Escola Nova (Claparède, Ferrière, Kerchensteiner, Maria Montessori, John Dewey, Alexander Neill, Cousinet, Freinet), da pedagogia institucional (Lobrot, Vasquez) ou, ainda, e já mais perto de nós, na área da educação de adultos pela obra e pelo testemunho do pedagogo brasileiro Paulo Freire.

Nos anos mais recentes, e por efeito da ascendência de outros temas ao palco dos debates pedagógicos, como, por exemplo, o tema das competências, a autonomia não tem concitado tantas atenções, ou, pelo menos, não tão intensas como em finais da década de 1990 e primeira metade da década passada. Ainda assim, a autonomia permanece viva como tema de debate. É um tema que ressurge hoje com novo fulgor, envolto em novos vocabulários, eles próprios dependentes de novas e inéditas ressignificações da autonomia.

O nosso objetivo, depois de dar profundidade histórica a esse tema, consiste em realizar um exercício de elucidação das luzes e das sombras que hoje envolvem o imaginário da autonomia em educação e em perguntar, neste terreno de incrustação, se ainda estamos dispostos a investir na autonomia e de que modo podemos fazê-lo.

\section{A autonomia: um imaginário individual e social à prova do tempo}

Enquanto imaginário individual e social da área cultural ocidental, a autonomia tem um longo historial. A vivência deste imaginário, como sublinha Castoriadis (1997, 
p. 73), “é uma experiência histórica que começa há cerca de vinte e cinco séculos e foi particularmente densa e rica nos últimos duzentos anos". A autonomia é certamente um imaginário que vem de longe, tanto na perspetiva social quanto individual. Mas o que é a autonomia enquanto imaginário? De que estamos falando quando tomamos a autonomia como imaginário? Que imaginário é esse que resiste à passagem do tempo e que ainda hoje está bem presente na educação?

Como se sabe, a noção de imaginário não é consensual entre os investigadores que a tomam como objeto de estudo, e estamos longe de acabar com a polêmica a seu respeito. Nesta matéria, como aliás em tantos outros assuntos da análise social e da reflexão antropológica, a convergência semântica é mais um sonho do que uma realidade. Na verdade, é uma vã ilusão procurar ortodoxias a propósito da noção de imaginário. Não há consensualidades robustas sobre o que significa imaginário e o melhor, para dar sentido explícito ao que se diz e ao que se faz, é definir essa categoria.

Como definir, pois, a noção de imaginário? Dado o alcance individual e social que queremos atribuir a essa noção, uma das vias mais promissoras de definição de "imaginário" é a que se encontra delineada em vários escritos de Cornelius Castoriadis, sobretudo em "Les carrefours du labyrinthe". Na obra, podemos constatar a radicalidade da noção de imaginário e como se pode ler em termos tanto sociais como individuais. Pelo lado do social, o imaginário é a sede ou a fonte da criação de formas novas que dão sentido ou significado ao mundo societário. Por outras palavras, é a instância que produz significações imaginárias sociais:

As significações imaginárias sociais criam um mundo próprio para a sociedade considerada; na realidade elas são este mundo e formam a psique dos indivíduos. Criam, assim, uma 'representação' do mundo, inclusive da própria sociedade e do seu lugar no mundo. (Castoriadis, 1997, p. 272).

O imaginário, na sua versão social, e ainda segundo o mesmo autor, não é propriamente a "produção de imagens, é a criação de um mundo humano" (Castoriadis, 2005, p. 106).

0 imaginário social, como sublinha noutro lugar, não é a criação de imagens na sociedade, não é o facto de pintar os muros da cidade. Uma criação fundamental do imaginário social, os deuses ou as regras do comportamento, não é nem visível nem mesmo audível, é simplesmente significável (Castoriadis, 1997, p. 96).

Esse imaginário não cria especificamente imagens, mas formas las quais podem ser imagens em sentido amplo), e essas formas são, sobretudo, aquilo que se designa por significações imaginárias. As significações imaginárias são as obras do imaginário social e chamam-se assim porque "não são, nem racionais (não as 
podemos 'construir logicamente') nem reais (não as podemos derivar das coisas); não correspondem a 'ideias racionais' nem a objetos naturais" (Castoriadis, 2005, p. 68). São imaginárias "porque derivam de uma criação, a saber, a imaginação". São sociais porque, resultando do imaginário social instituinte de cada unidade social, "não são nada se não são partilhadas, participadas, por este coletivo anónimo, impessoal, que é também, de cada vez, a sociedade" (Castoriadis, 2005, p. 68).

A história humana, e também as diversas formas de sociedade que conhecemos nesta história, é essencialmente definida pela criação imaginária. Não se pense, porém, que “imaginário”, neste contexto, significa fictício ou ilusório. É antes o adiantamento ou a posição de formas novas:

Estas formas, criadas por cada sociedade, fazem nascer um mundo no qual a sociedade se inscreve e se atribui um lugar. É por meio delas que a sociedade constitui um sistema de normas, de instituições no sentido amplo do termo, de valores, de orientações, de finalidades da vida coletiva assim como da vida individual. No âmago dessas formas encontram-se, invariavelmente, as significações imaginárias sociais, criadas pela sociedade, e que as suas instituições encarnam. (Castoriadis, 1996, p. 159).

Significações imaginárias sociais são, por exemplo, "novos valores, novas normas, novas formas de dar sentido às coisas, às relações entre os seres humanos, à nossa vida em geral" (Castoriadis, 2005, p. 88).

A forma como Castoriadis entende o imaginário individual não anda longe dessa caraterização do imaginário social. Se o produto do imaginário continua a ser a significação imaginária, recorrentemente declinada no plural, agora a instância da produção ou criação é a psique individual. Também a psique individual, através da imaginação radical, produz um mundo de significações próprias: "0 primeiro trabalho da imaginação radical da psique consiste em fazer nascer um mundo de formas" (Castoriadis, 1997, p. 225). A sede da criação de formas, no caso do imaginário social, é o "coletivo anónimo e, mais geralmente, o campo social-histórico". No indivíduo singular, "é a imaginação radical, quer dizer, a dimensão determinante da sua alma”, ou seja, a psique (Castoriadis,1997, p. 228). Se as significações imaginárias sociais, produto do imaginário coletivo e cristalização da sua força criativa, preenchem de sentido a existência comunitária e definem as maneiras de fazer de uma dada sociedade, as significações imaginárias individuais, resultantes do imaginário individual e sua expressão concreta, conformam por sua vez o mundo próprio do sujeito e delimitam um mundo para si.

Em ambas as situações, temos que o imaginário se consubstancia em significações imaginárias. As significações imaginárias, tanto individuais como sociais, são o rosto 
visível do imaginário, e em termos do autor referido, a autonomia é um imaginário porque exprime, pelo menos desde a antiguidade grega, uma poderosa significação imaginária.

0 imaginário da autonomia, segundo Castoriadis (1986, p.236), não é de facto uma significação imaginária recente. Remonta pelo menos à Grécia Antiga e à época em que se institucionalizou, ainda que imperfeitamente, a polis democrática. Esta foi, supostamente, a primeira vez que o imaginário da autonomia irrompeu na história, e foi preciso esperar pelo fim da Idade Média para que reemergisse pela segunda vez, aquando da constituição, por parte da protoburguesia, das primeiras comunas livres.

Nos dois casos, e sobretudo de lá para cá, a autonomia adquire o "sentido de uma autoinstituição da sociedade, autoinstituição doravante mais ou menos explícita: fazemos as leis, sabemos que é assim, e somos assim responsáveis das nossas leis e temos que perguntar, de cada vez, porquê esta e não outra lei?" (Castoriadis, 1986, p.237). Dado que a autonomia social é indissociável da individual (Castoriadis, 2005, p.17), “Isso implica, evidentemente, também o surgimento de um novo tipo de ser histórico no plano individual, quer dizer, um individuo autónomo, que pode perguntar, e perguntar em voz alta: será que esta lei é justa?" (Castoriadis, 1986, p.237).

Esta criação histórica da autonomia dá origem a um ser capaz de questionar a ordem social existente e de questionar a si mesmo, pondo em questão as leis da sua própria existência. 0 que se passa com essa criação é uma verdadeira ruptura com o estado de heteronomia alienante e desresponsabilizadora, primeiro da sociedade e depois do indivíduo.

A ruptura aconteceu e permanece viva ainda nos dias de hoje. Desde o momento grego inaugural e da centelha medieval, outros momentos pautaram essa ruptura com a heteronomia. Assinalamos dois que nos parecem decisivos: o momento moderno (em torno do iluminismo, de Kant e de Rousseaul e o momento contemporâneo (momento da afirmação do direito a uma vida independente e de uma revolução copernicana em educação).

0 momento grego, que é também o da democracia e da filosofia, tem na polis e em Sócrates duas fulgurantes expressões do imaginário anti-heteronomia. Na polis, porque a cidade autoinstitui as suas normas e nelas se revê por inteiro. Assume-se, portanto, como coletividade política que se governa a si mesma. Em Sócrates, porque em vez de se submeter à tradição e à autoridade, argumentou uma posição própria e defendeu a importância, se não a necessidade, de pensar e argumentar por si mesmo. Ou seja, porque pugnou (e deu o exemplo) da autonomia do pensamento, da atividade intelectual independente. A sua pedagogia era já um assomo de pedagogia da autonomia, pois instigava o exame crítico de si mesmo, o pensamento crítico, a indagação autónoma e a defesa de uma posição própria. 
0 momento moderno do imaginário da autonomia também teve as suas expressões fulgurantes e uma delas foi o iluminismo. 0 seu lema foi pensar por si mesmo e nada aceitar sem antes passar pelo crivo da razão. Quando em 1784 perguntaram a Kant: “0 que é o iluminismo?", ele simplesmente respondeu: sapere aude, quer dizer, ousa pensar ou saber por ti mesmo, tem a coragem de usar a própria razão para produzir saber ou conhecimento. Kant, o iluminista, "viu nesta emancipação o sinal de que se saiu, efetivamente, do estatuto de 'menor' e que se atingiu, moralmente, a maturidade" (Hameline, 1999, p. 55), ou seja, que se alcançou a autonomia racional e moral que ele tanto tematizou na "Crítica da razão pura" e na "Crítica da razão prática". Já com Rousseau, e nesta fase da "modernidade sólida" (Bauman, 2003, p. 8), vemos como se afirma uma pedagogia da autonomização e da emancipação, em parte descrita e em parte sugerida no "Emílio", de 1762. Aí, o filósofo das metáforas e das antinomias apresenta os elementos de uma educação destinada a transformar a criança num ser autónomo, capaz de formar os seus próprios critérios independentes e de resolver problemas práticos pelos seus próprios meios, sem necessidade de recorrer à autoridade.

Sob os auspícios de Rousseau vão-se formular, na transição do século XVIII para o século XIX, aqueles que ficariam conhecidos como os princípios diretores da ação e da reflexão pedagógica visando a perfectibilidade e a autonomia. Por um lado, o princípio da autodeterminação do educando no que concerne à configuração ou à modelação do seu destino e, por outro, o princípio do incitamento externo à autonomia (Benner, 1998, p. 47-48). Será a esta luz que se vai desenvolver, mais adiante, e já na época contemporânea, aquilo que se convencionou chamar "revolução copernicana em educação", a começar na educação de tenra idade e a estender-se, paulatinamente, a todas as idades do ciclo vital: crianças, jovens, adultos e idosos.

0 momento contemporâneo do imaginário da autonomia é de tal maneira rico e diversificado que não temos a veleidade de sinalizar todas as suas manifestações. Retenha-se, no entanto, essa revolução copernicana em educação, protagonizada pelos mestres pedagogos da Escola Nova ou Educação Nova, pelos promotores da pedagogia institucional, da pedagogia não diretiva e pelos defensores/inspiradores de uma educação de adultos emancipadora ou libertadora. Não obstante as diferenças de conceptualização e de justificação, todos colocam o educando no centro do processo educativo e ambicionam para a educação, independentemente da idade, a autonomia como última meta.

A par desta ampla afirmação do imaginário da autonomia em educação, correspondente à posição de uma nova forma de promover o desenvolvimento humano, convém sublinhar que a época contemporânea, na sua agenda inovadora, consagra explicitamente o direito a uma vida independente, e isso desde logo no preâmbulo da Convenção dos Direitos da Criança (1989), quando se diz que “a criança 
deve ser plenamente preparada para uma vida independente na sociedade". A mesma ideia, e com anterioridade, aparece na Declaração Universal dos Direitos do Homem (1948) quando se reitera que o indivíduo, independentemente de qualquer pertença ou filiação, é livre e tem direito à liberdade, à independência de juízo ou critério.

Embora a traços largos e de maneira impressionista, como convém a uma curta dissertação, vemos que o imaginário da autonomia está incrustado na nossa história e que resiste à passagem do tempo. Trata-se de um imaginário com tradução tanto ao nível social como individual, e é nesta última vertente que agora gostaríamos de insistir, abordando o manto de ambiguidade que a parece envolver na atualidade.

\section{Entre luz e sombras: o imaginário da autonomia na atualidade}

A vertente individual do imaginário da autonomia está presente nas atuais metas da educação e recebe um importante apoio da sociedade. Até parece que, dado o seu prestígio social atual, essa vertente do imaginário da autonomia não precisa de justificação e argumentação: "Nascemos e crescemos numa sociedade absolutamente 'individualizada' em que a autonomia individual e a independência são axiomas que não exigem (nem admitem) discussão e demonstração" (Bauman, 2011, p. 155).

Na sociedade fortemente individualizada da atualidade, e nas circunstâncias que a rodeiam, a autonomia é de facto um imaginário em franca valorização. A autonomia soa bem e recebe apoio de múltiplos quadrantes, às vezes diametralmente opostos no espectro político das ideologias reinantes. A autonomia é um valor em alta e isso interroga: por que será? A que se deve semelhante apreço pelo imaginário da autonomia? Será apenas por razões humanistas, subitamente descobertas para aprofundar a humanidade do homem? Ou será por razões mais prosaicas, que têm a ver com os imperativos do contexto? Atualmente, dizem-nos Beck e Beck-Gernsheim (2003, p. 72), “proliferam as diretrizes - no sistema educativo, no mercado de trabalho ou no Estado de bem-estar - que contêm a exigência de que o indivíduo tome as rédeas da sua própria vida sob pena de sanção económica". Será o apreço pela autonomia, enquanto imaginário, uma resposta a esta exigência do presente?

A resposta é certamente matizada mas não pode ignorar essa pressão do contexto. Importa sublinhar que o contexto apela insistentemente à autonomia dos indivíduos e que difunde aos quatro ventos o ideal normativo de indivíduo autónomo, senhor de si mesmo e do seu destino, gestor do seu projeto de vida e responsável por tudo aquilo que the acontece: inserção na vida ativa, permanência no posto de trabalho, queda na exclusão e na marginalidade, sucesso e insucesso nos estudos, posicionamento no sistema da desigualdade, riqueza e pobreza, saúde e doença, reconhecimento e discriminação. 
0 valor normativo do indivíduo autónomo, dando força a essa tendência que consiste em responsabilizar as pessoas por todas as emergências e todas as contingências da vida, inclusive no terreno da educação e da formação com as noções de autoaprendizagem, de aprendizagem autodirigida e de educação e formação ao longo da vida, não se pode interpretar à margem do discurso neoliberal imperante, uma vez que esse discurso, aspirado pelo imaginário do "eu autossuficiente", é quem mais conclama à autonomia hoje em dia. É um discurso que pressupõe, contra todas as evidências estabelecidas pela ciência e pelo senso comum, que "os indivíduos podem dominar, por si próprios, a totalidade das suas vidas, e que obtêm e renovam a sua capacidade de ação a partir do seu interior" (Beck e BeckGernsheim, 2003, p. 29).

A ideia neoliberal de indivíduo autónomo, amplamente disseminada no mundo atual e verdadeiramente hegemónica sobre muitas consciências, ressignifica o imaginário da autonomia e traduz-se, entre outras noções, nos conceitos de "eu empreendedor", "eu gestor e cuidador de si mesmo", "eu responsável" e "eu autossuficiente".

Aparentemente, estas ressignificações são bem-intencionadas e parecem colocar-se na linha de reforço e de revalorização do sujeito, tanto mais quanto este se confronta, hoje em dia, com situações de instabilidade, precariedade, incerteza e volatilidade, não só no mundo das transações económicas e do emprego, como também na esfera das relações humanas. Afinal, para se movimentar nesse "novo mundo", o indivíduo não perde nada em ser mais responsável, mais autossuficiente, mais empreendedor e com mais capacidade para gerir os vários aspetos da política vital, aí incluindo o seu bem-estar.

Se as redefinições neoliberais da autonomia fossem por aí, todas as suspeitas resultariam infundadas e nada haveria que apontar. A verdade, porém, é outra. Há fundadas suspeitas, para não dizer comprovações quotidianas, de que as redefinições neoliberais do imaginário da autonomia se prestam a vários usos instrumentais: por um lado, legitimam a transferência de responsabilidades estatais para as esferas individuais, nomeadamente em termos de segurança e bem-estar pessoal. "Que o indivíduo trate de si mesmo", parece ser esta a mensagem implícita nos incessantes apelos ao autogoverno, à autodireção, ao autocontrolo, à responsabilização pessoal, ao cuidado de si, à autossuficiência e ao empreendedorismo. Por outro lado, essas redefinições servem de estratégia ao controlo do corpo social, especialmente de pessoas e grupos marginalizados, por parte da autoridade governamental, na medida em que as culpabiliza por não estarem, supostamente, à altura das circunstâncias.

Uma das formas usadas pelo poder dominante para obter o consentimento das pessoas e grupos dominados é culpar esses coletivos marginalizados, a cada uma 
dessas pessoas, pelo 'seu fracasso', não do 'nosso fracasso', tornando-os únicos responsáveis do seu próprio destino (Torres Santomé, 2010, p. 253).

A responsabilização, na verdade uma sobrerresponsabilização quando não se dispõe de condições e recursos que só a coletividade pode disponibilizar, se não se pode fazer de modo explícito, leva-se a cabo implicitamente, atribuindo aos grupos sociais etiquetados negativamente, o controlo da sua sorte; são apresentados como autónomos, únicos responsáveis do seu destino e, consequentemente, os seus problemas são atribuídos a falhas de personalidade, a escolha própria ou a fracasso pessoal.

O vocabulário neoliberal da autonomia, resultado dessa operação de transmutação de significados, parece vincular a autossuficiência, a responsabilização pessoal, a autodeterminação, o cuidado de si e o eu empreendedor a um projeto de empowerment, único capaz de reatar, sob nova luz, a inspiração original da significação imaginária da autonomia. Na prática, o que faz é colocar o indivíduo sob a férula da arte neoliberal de governar, a qual consiste em obrigar as pessoas a governarem-se a si mesmas, tenham ou não recursos para levarem a cabo essa difícil tarefa. Essa arte “interpela os indivíduos como sujeitos empresariais em todas as esferas da vida" (Brown, 2005, p. 41) e espera que sejam sejam eles a preencher todas as suas necessidades, na saúde e na doença, no ócio e no tempo livre, na vida ativa e na reforma, no desemprego e na indigência, na educação e na formação.

A governamentalidade neoliberal, para cumprir com os seus objetivos, aposta em formas de individualismo competitivo e autocentrado que celebram, sobretudo em tempos de crise, as virtudes da competição interpares, os fins lucrativos, a prosperidade material e os interesses pessoais. Assim, como sublinha Giroux,

o âmbito público é cada vez mais reduzido a um espaço instrumental no qual a individualidade limita o autodesenvolvimento à busca implacável de interesses pessoais, e o âmbito da autonomia é reduzido a um domínio de atividade no qual podem ser perseguidos objetivos privados de tipos diversos. (Giroux, 2011, p. 71-72).

A essa luz, a competitividade substitui a solidariedade, e as pessoas "veem-se abandonadas aos seus próprios recursos, penosamente escassos e obviamente insuficientes" (Bauman, 2007, p. 14).

A arte neoliberal de governar, impondo uma autodeterminação obrigatória e uma assunção individual dos riscos da vida do dia a dia, revê-se na ideologia da privatização e a ela se vincula como a um programa estratégico. De que ideologia se trata? Segundo Bauman (2009, p. 112-113), o que está em causa nessa ideologia é um sistema de crenças segundo as quais é pura perda de tempo preocupar- 
se com a sociedade, com o bem comum lessa preocupação é irrelevante para a felicidade individual e para o êxito na vidal e, ato contínuo, ridiculariza o princípio da responsabilidade coletiva pelo bem-estar dos seus membros. Proclama, ainda, a inutilidade (na realidade, a contraprodutividade) da solidariedade. 0 que as pessoas têm que fazer, segundo essa ideologia, é tratarem de si mesmas, pensarem em si mesmas e procurarem soluções individuais para problemas criados socialmente. Os indivíduos, nessa ideologia, são os únicos responsáveis da sua situação individual, tanto no êxito como na adversidade.

Sob o império da ideologia da privatização "não há mais salvação pela sociedade. É ao indivíduo que cabe administrar os seus assuntos, os assuntos do dia a dia" (Bauman, 2003, p. 35). Se as coisas correm mal, é a si que tem que culpabilizar, e não a sociedade ou os poderes públicos. Assim, fica sujeito a uma obrigação de responsabilização que desvirtua, ou torna problemática, a competência em autonomia quando falham as capabilities e os recursos individuais.

Um passo mais e dir-se-ia que o indivíduo fica refém de uma obrigação de autonomia, a vários títulos contraditória com a vocação original desse imaginário e, além disso, mais do que suspeita nas circunstâncias atuais. Por estas razões, impõese abrir novas questões a propósito do imaginário da autonomia, especialmente quando se equaciona a sua promoção através da educação.

\section{0 que queremos da autonomia? Vale a pena investir nesse imaginário? De que modo?}

A formulação destas questões pode parecer impertinente e algo provocatória, mas a verdade é que não podemos fazer a sua economia, em particular quando surgem grandes dúvidas sobre a bondade das mais recentes ressignificações do imaginário da autonomia. Afinal, que expectativas é que nutrimos em relação a esse imaginário, ou o que é que queremos dele, quando se coloca a questão da sua promoção através da educação? Não é certamente a mesma coisa afirmar que se quer reatar com a sua inspiração original, a do empowerment, resgatando-a de apropriações indevidas, ou então, alinhar pelas suas novíssimas redefinições, subordinando a educação a um conjunto de valores e injunções que pouco ou nada têm a ver com essa inspiração originária.

A opção formula-se sob o signo da luz e das sombras: ou seguimos a via da capacitação, reforçando poderes de decisão e autodireção, de modo a criar condições à plena realização do ser humano, ou alinhamos pela ficção da autossuficiência e, então, enveredamos pela submissão do ser humano a lógicas instrumentais e desumanizadoras. De que lado é que estamos? Do lado do respeito e da valorização do 
ser humano, entendendo este como sujeito que intervém ativamente na configuração do seu destino, não isoladamente, mas com a solidariedade de outros sujeitos e de outros atores sociais, eles próprios com a "vocação ontológica de ser mais" (Freire, 1975, p. 58), ou do lado da sua usurpação e instrumentalização?

Se o lado mais luminoso do imaginário da autonomia é aquilo que queremos, quanto mais não seja para levar adiante, e nas atuais circunstâncias, o ideário que incorpora desde os antepassados gregos, então, precisamos de adequar a educação às ideias de liberdade, autodeterminação e autorrealização.

De que modo é que se poderia fazer isso? À luz de J. M. Puig y X. Martín (2007), e da sua obra "Competencia en autonomia e iniciativa personal", além de toda a rica tradição da pedagogia de projetos (Vassileff, 1991), isso poderia ser feito e operacionalizado dando novo fôlego e energia a uma pedagogia em torno de projetos educativos, tanto na escola como fora dela. 0 desenvolvimento destes projetos, à margem das conhecidas derivas tayloristas, ajusta-se à promoção da autonomia, uma vez que proporciona a experimentação da tomada de decisões, a assunção de responsabilidades, o empreendedorismo, a inovação, a criatividade, a cooperação, a formulação de perguntas e a busca de soluções, a superação de obstáculos, a autoestima e o reforço do sentimento do valor próprio (Puig y Martín, 2007, p. 149151).

O envolvimento em projetos educativos, de investigação e/ou de intervenção, é uma oportunidade para adquirir esses fundamentais da autonomia, porém, para se tornar realidade, conviria respeitar, enquanto educadores, certos princípios orientadores e assumir, simultaneamente, um conjunto de tarefas de mediação. “É necessária a intervenção de um adulto para se aproveitar, ao máximo, as potencialidades desta metodologia" (Puig y Martín, 2007, p. 151). No capítulo dos princípios orientadores, e tendo em conta a interessante sistematização de Eric Boukobza (1998, p. 76-80) sobre fatores de sucesso em atividades e projetos com jovens europeus de vários Estados membros do Conselho da Europa, o adulto mediador poderia aderir, com vantagem, aos seguintes:

- É importante que os projetos se façam com os educandos, e não para eles, quanto mais não seja por coerência com os propósitos da autonomização.

- É apropriado que as equipas de projeto revelem homogeneidade etária e sejam de pequena dimensão.

- Convém evitar distinções de sexo, raça, classe social, recursos económicos e identidade cultural.

- Os educandos, individual ou coletivamente, seriam os verdadeiros gestores dos projetos, não obstante o indispensável apoio do adulto mediador. 
- Seria necessário encorajar a autonomia dos educandos e respeitá-los nos planos da criação e da ação desde a fase inicial dos projetos.

- Convém lutar contra o isolamento narcísico, promovendo a comunicação interindividual e a livre circulação de informações.

- Os projetos seriam mais motivadores se houvesse a preocupação de os dividir em pequenas sequências e se conduzissem, regularmente, a resultados concretos.

- Em atividades curriculares escolares, os projetos adquirem maior pertinência se inscritos na (e articulados com al cintura sociocultural da escola. São de privilegiar, nessa ordem de ideias, implicações e transações com a envolvência geográfica da instituição escolar.

- A pedagogia de apoio a projetos individuais e coletivos, visando à autonomização, ou ao reforço da competência em autonomia, assentará com vantagens nos princípios da confiança, da responsabilização, da delegação de poderes e de autoridade, evitando assim as tentações paternalistas e o assistencialismo junto dos protagonistas da ação.

Relativamente às tarefas de mediação, na ausência das quais dificilmente passaríamos da generalidade dos princípios orientadores, o processo, de acordo com a obra de Chesnais "Vers l'autonomie: l'accompagnement dans les apprentissages" (1998), poderia passar pelas seguintes fases ou etapas:

\section{Fase de explicitação e negociação}

Aqui, a tarefa consiste em ajudar o educando a expressar as suas intenções, os seus desejos, as suas ideias, sobre projetos pessoais a realizar. Consiste, ainda, em mediar a negociação de projetos coletivos em contextos formais e não formais.

\section{Fase de motivação e preparação}

O objetivo, nesta fase, é suscitar a implicação na realização do projeto negociado, ajudando a descortinar o seu sentido, a sua utilidade, o seu benefício. É, também, a fase de apoiar a elaboração de um plano de ação depois de uma reflexão sobre os meios necessários à realização do projeto.

\section{Fase de realização}

Aqui é preciso incentivar a análise detalhada das tarefas e ajudar o educando, ou os membros do grupo, a dosear os seus esforços em função das suas possibilidades. E, ainda, acompanhar a concretização das atividades, fazendo o ponto da situação relativamente ao propósito inicial e fornecer, se necessário, estímulo e apoio metodológico. 


\section{Fase de balanço e transferência}

Nesta última fase, perseguem-se dois objetivos: por um lado, seria interessante fomentar e apoiar uma avaliação do trabalho efetuado, chamando a atenção para as estratégias utilizadas, e ajudar a tirar ilações para o futuro. Por outro, é conveniente estimular a transferência de estratégias usadas na realização do projeto, solicitando ao educando - ou aos educandos, se se tratou de projeto coletivo - a escolha de situações em que seriam pertinentes e como pensa(m) usá-las.

A mediação para a autonomia, muito provavelmente, não se esgota na implementação dessas tarefas e pode ser que dependa da convocatória de outros princípios orientadores resultantes de outras práticas e de outras conceptualizações. Ainda assim, pode ser uma ajuda preciosa num projeto de empowerment, tal como está implícito no lado mais atrativo e sedutor do imaginário da autonomia, e que se pode definir nestes termos:

processo individual e organizativo através do qual as pessoas se tornam 'potentes' (empowered), quer dizer que reforçam a sua própria capacidade de escolha e de autodeterminação, desenvolvendo paralelamente o sentimento do valor próprio e da própria autoestima. (Alberici; Serreri, 2005, p. 41).

O educador é sempre indispensável na consecução desse projeto, embora precise de um bom enquadramento institucional e de uma boa infusão na pedagogia de projetos de investigação e/ou intervenção. Há, pois, que contar com ele se queremos rearticular a educação com o imaginário da autonomia, precisamente numa altura em que pairam muitas sombras sobre o lado mais interessante desse imaginário.

\section{Considerações finais}

Como vimos, o imaginário da autonomia resiste à passagem do tempo e ainda hoje tem um grande poder de atração em educação. Não obstante, as suas mais recentes ressignificações, em termos de responsabilização individual, autossuficiência, cuidado de si mesmo, empreendedorismo e autodeterminação obrigatória, levantam a suspeita de que esse imaginário está a ser desvirtuado pela sua colocação ao serviço de interesses que não se coadunam com a promoção do ser humano. Assim, aquilo que devia levar a um projeto de empowerment, ou seja, a um reforço dos poderes e das capacidades de autogoverno e de autodeterminação, acaba por negar esse projeto e desse modo ensombrar o imaginário da autonomia nas circunstâncias e nas condições sociais de uma "modernidade líquida" (Bauman, 2003) que desafia permanentemente a viver na instabilidade, na incerteza e na precariedade do dia a dia. 
A fim de resgatar a inspiração original desse imaginário, importa assumi-lo nas suas luzes emancipatórias e ser consequente quando se concebe a educação sob os seus auspícios. De que modo? Investindo eventualmente numa pedagogia de projetos de investigação e/ou intervenção, tendo em conta os princípios orientadores e as tarefas de mediação que sugerimos na última secção, ou seja, quando perguntamos se ainda vale a pena investir no imaginário da autonomia, não obstante as suas redefinições.

0 imaginário da autonomia, na sua vocação de empowerment, tem um longo futuro à sua frente. Compete-nos a nós, educadores em contextos formais e não formais, manter acesa a chama desse imaginário, implementando e realizando projetos onde se tenha a oportunidade de aprender a deliberar, a assumir responsabilidades, a inovar, a criar, a cooperar, a formular perguntas e a buscar soluções, a superar obstáculos e a elevar a autoestima.

\section{Referências}

ALBERICI, Aureliana; SERRERI, Paolo. Competencias y formación en la edad adulta: el balance de competencias Barcelona: Laertes, 2005.

BAUMAN, Zygmunt. Modernidad líquida. Buenos Aires: FCE Argentina, 2003. . Confianza y temor en la ciudad. Barcelona: Arcadia, 2007. . El arte de la vida. Barcelona: Paidós, 2009. . 44 cartas desde el mundo líquido. Barcelona: Paidós, 2011.

BECK, Ulrich; BECK-GERNSHEIM, Elisabeth. La individualización: el individualismo institucionalizado y sus consecuencias sociales y políticas. Barcelona: Paidós, 2003.

BENNER, Dietrich. La pedagogía como ciencia. Teoría reflexiva de la acción y reforma de la praxis. Barcelona: Pomares - Corredor, 1998.

BOUKOBZA, Eric. Clés pour la participation: guide à l'usage des praticiens. Strasbourg: Conseil de l'Europe, 1998.

BROWN, Wendy. Edgework: critical essays on knowledge and politics. Princeton: Princeton University Press, 2005.

CASTORIADIS, Cornelius. Domaines de l'homme. Les carrefours du labyrinthe II. Paris: Seuil, 1986.

. La montée de l'insignifiance. Les carrefours du labyrinthe IV. Paris: Seuil, 1996. . Fait et à faire. Les carrefours du labyrinthe V. Paris: Seuil, 1997.

. Une société à la dérive. Entretiens et débats 1974-1997. Paris: Seuil, 2005. 
CHESNAIS, Marie. Vers l'autonomie: l'accompagnement dans les apprentissages. Paris: Hachette, 1998.

FREIRE, Paulo. Pedagogia do oprimido. Porto: Afrontamento, 1975.

GIROUX, Henry. Contra o terror do neoliberalismo. A política para além da era da ganância. Mangualde: Pedago, 2011.

HAMELINE, Daniel. Autonomie. In HOUSSAYE, Jean. (Coord.). Questions pédagogiques. Encyclopédie historique. Paris: Hachette, 1999, p. 47-58.

PUIG, Josep María; MARTíN, Xus. Competencia en autonomía e iniciativa personal. Madrid: Alianza Editorial, 2007.

TORRES SANTOMÉ, Jurjo. La justicia curricular. El caballo de Troya de la cultura escolar. Madrid: Morata, 2010.

VASSILEFF, Jean. La pédagogie du projet en formation jeunes et adultes. Lyon: Chronique Sociale, 1991.

Recebida $1^{\text {a }}$ versão em novembro de 2011

Aprovada $2^{\mathrm{a}}$ versão em abril de 2012

Manuel Gonçalves Barbosa, doutor em Educação pela Universidade do Minho, Braga, Portugal. Professor Associado na Universidade do Minho, vinculado ao Instituto de Educação e ao Departamento de Teoria da Educação e Educação Artística e Física. Integra o Centro de Estudos em Educação (Cied) e coordena o projeto Educação, Cidadania e Sociedade Civil. Publicações recentes: A educação em arenas sociais multiculturais. Revalorização do papel da sociedade civil (2011); Educação e imaginário intercultural: recomposição do papel da sociedade civil (2012). E-Mail: mbarbosadie.uminho.pt 